\title{
O Livro dos Regimentos dos Oficiais Mecânicos e os estudos arquitetônicos da Biblioteca Nacional de Portugal: uma interpretação
}

Angela Brandão*

Universidade Federal de São Paulo

\begin{abstract}
Resumo
O Livro dos Regimentos dos Oficiais Mecânicos, manuscrito do século XVI, onde se compilaram leis consuetudinárias (que regiam os trabalhos artesanais em Portugal, desde à Idade Média), faz referência a desenhos-modelo para a realização dos exames dos ofícios. No entanto, ao observarmos o original conservado no Arquivo da Câmara de Lisboa, não localizamos quaisquer desenhos, o que nos levou a deduzir que seriam papéis avulsos. A coleção de desenhos com motivos arquitetônicos conservada na Biblioteca Nacional de Portugal não traz resposta definitiva para 0 problema, mas indica um caminho de reafirmação, no século XVIII, da exemplaridade das ordens clássicas.
\end{abstract}

\section{Palavras-chave}

Livro dos Regimentos; ofícios mecânicos; Tratados de Arquitetura; Ordens Clássicas; desenhos; Biblioteca Nacional de Portugal.

\begin{abstract}
The Regiments Book of Craft Works, manuscript of the sixteenth century, compiled to customary laws (that ruled the craft works in Portugal, from the Middle Ages), makes reference to model designs for the crafts exams. However, when we observe the original preserved in the Archives of Lisbon, we did not find any drawings, which led us to deduce that they would be loose papers. The collection of drawings with architectural motifs conserved in the National Library of Portugal brings no definitive answer to the problem, but indicates a way to understand a reaffirmation of the exemplary of the classical orders, in the eighteenth century.
\end{abstract}

\section{Key-words}

Regiments Book, crafts work, Architecture Treaties, Classical Orders, drawings, Nacional Library of Portugal.

\footnotetext{
* Professora do Departamento e do Programa de Pós-Graduação em História da Arte, Universidade Federal de São Paulo (UNIFESP). Esta pesquisa conta com apoio do CNPq Edital Universal 14/2013 Faixa C n. 471680/2013-3. 
Couza $\mathrm{m}^{\text {to }}$. Necessaria aos Pintores, Escultores e Arquitectos; porque todas

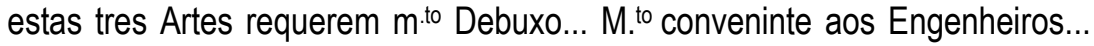
Aos ourives do Ouro e da Prata muy necessario, pois he lastima estejam segos em sua ignorancia... Necessitando de entender a Arquitectura, e essa deixão à descripção do Marceneiro q faz a madeira $p^{\text {a }}$ se vazar de prata sem conhecim $^{\text {to }}$ do que se lhes obra. Parte essecial aos Entalhadores, para fazerem o relevo de talha com propriedade, e inventarem com graça e sciencia as fabricas dos retabolos.... (...) Aos Marceneiros, $p$.a fazerem os Contadores, Leitos, bufetes, e mais com boa invenção; entenderem bem as plantas e riscos de outrem, e fazerem elles mesmos boas invenções e riscos... E não há Arte nem ofício, q em todo ou em parte não dependa da Arte do Debuxo".

Félix da Costa, Antiguidade da Arte da Pintura, 1685-1688.

O modelo de organização do trabalho artesanal que se mantinha em Portugal desde a Idade Média, com características das corporações de ofícios, permaneceu e foi aplicado no Brasil, por meio de uma série de regras, de caráter fortemente consuetudinário. Tal modelo determinou a produção artesanal que, em grande medida, confundiu-se com o que hoje entendemos como produção artística. Essas regras se reuniram no manuscrito compilado em 1572: Livro dos Regimentos dos officiaes mecanicos da mui nobre e sëpre leal cidade de Lixboa ${ }^{1}$, cujo original encontra-se hoje no Arquivo da Câmara Municipal de Lisboa.

O manuscrito, que resultara da compilação de regras vigentes, oriundas da Idade Média e foi copiado e distribuído pelas distintas cidades e câmaras portuguesas, assim como, por certo, entre suas colônias; acrescentado, em distintas datas, por novas leis e modificações ainda no decorrer do XVIII. No entanto, em sua totalidade, manteve-se como o conjunto mais geral de regras para o exercício das atividades artesanais no contexto luso-brasileiro até finais do século XVIII2. O Livro dos Regimentos foi transcrito, em 1926, por Carlos José de Araújo Vilela, apresentado por Vergílio Correia e impresso, pela primeira vez, em Coimbra, junto à Imprensa da Universidade (Correia, 1926).

Os Regimentos indicavam a existência de cento e uma profissões artesanais, organizadas no sumário da transcrição por ordem alfabética (Correia, 1926). Estariam relacionadas com as criações artísticas, concebidas como fazeres artesanais: carpinteiros de casas, carpinteiros de tendas, douradores, ensambladores, entalhadores, torneiros, ourives do oro e ourives da prata, batifolhas, picheleiros (que trabalhavam com estanho), pedreiros, pintores, tapeceiros e tecelões, e mesmo profissões como padeiros ou cozinheiros (Brandão, Domenech,Yang: 2014 A; Domenech, Yang: 2014 B). As atividades

\footnotetext{
${ }^{1}$ Livro dos Regimentos dos officiaes mecanicos da mui nobre e sëpre leal cidade de Lixboa. Arquivo da Câmara Municipal de Lisboa.

2 Na página VI se lê: "acrescentou alguém com letra que suponho seja já do século XVII: 'os originais se entregaram neste tempo aos juízes de ofício e ainda hoje muitos se conservam'."

VIS Vol.15, n²/julho-dezembro de 2016

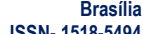
ISSN (versão eletrônica):2447-2484
} 
de pintura e escultura aparecem ainda regradas pelos Regimentos, na compilação de 1572, no entanto, sabe-se que os escultores e pintores, no decorrer dos séculos XVII e XVIII, alcançavam um estatuto profissional mais independente, em Portugal, das ordenanças dos ofícios, aproximando-se muitas vezes a profissionais liberais (Oliveira, 2006: 175; Araújo, 2005: 50).

A observação do Livro dos Regimentos dos officiaes mecânicos da mvi nobre e sépre leal cidade de Lixboa, como uma compilação de séries de leis manuscritas do século XVI, mas emolduradas pela tradição medieval, reunidas em 1572 e depois acrescentadas de modificações nos séculos seguintes, como temos visto, permite reconhecer as profissões que atuaram artisticamente em Portugal e no Brasil, assim como os princípios que determinavam seus procedimentos.

Todo o sistema de controle dos trabalhos artesanais orbitava em torno das Câmaras Municipais, seja nas cidades de Portugal, seja nas cidades de suas colônias. Cada grupo de profissionais deveria eleger seu "Juiz de Ofício" (Correia, 1926: 1 e ss.). Tal sistema de trabalho previa também a presença dos aprendizes, sobre os quais os mestres exerciam um importante controle, no sentido de que um artesão não poderia chamar a trabalhar para si um aprendiz "pertencente" a outro oficial: "nenhum oficial de dito ofício será tão ousado que tome nem recolha em sua casa aprendiz ou obreiro que esteja com outro oficial enquanto durar o tempo que tal obreiro ou aprendiz seja obrigado a estar com seu amo (Correia, 1926: 24)". Também se buscava limitar o número de aprendizes em cada ateliê. $O$ capítulo relativo aos pedreiros e carpinteiros dizia:

E ordenam que nenhum pedreiro ou carpinteiro seja tão ousado que tenha cada um mais de dois criados aprendizes para que se lhes possam ensinar e cuidar-lhes de perto e ver continuamente 0 que estão fazendo e por muito engano que se segue ao pouco que os mestres ponham as mãos nas obras quando tem mais aprendizes que os ditos dois [sem grifo no original] (Correia, 1924: 107).

Depois de exercitar-se como aprendiz junto a uma tenda, o aspirante a artesão poderia apresentar-se para realizar o exame correspondente à profissão que se preparava para exercer. $O$ ensino das artes se fazia, portanto, diretamente nas oficinas, tendas ou logias, ou mesmo nos canteiros das obras, onde 0 mestre transmitia seu conhecimento aos aprendizes, muitas vezes seus filhos ou parentes (Campos, 2006: 35). Os também chamados "moleques" recebiam o ensinamento prático entremeado, provavelmente, da transmissão de saberes teóricos, pelo que se pode imaginar diante da complexidade das matérias exigidas para os exames em diferentes profissões, como se verá adiante (Brandão, 2014). 
Uma vez tendo aprendido seu ofício, como moleque numa tenda, logia ou no canteiro de obras, o artesão poderia estabelecer seu próprio negócio, desde que aprovasse o exame de oficio. "Que nenhum oficial mecânico ponha tenda nesta cidade sem primeiro ser examinado (Correia, 1926: 234)", determinava o Livro dos Regimentos. Este exame se faria na casa do juiz do ofício, diante dele e de dois artesãos já examinados, que exerciam aquela determinada profissão. Se as peças executadas pelo artesão não fossem bem feitas, de acordo com as regras dos Regimentos e, ainda assim, fosse aprovado 0 candidato, o juiz seria multado. Caso 0 artesão não lograsse realizar a peça para comprovar sua capacidade, poderia apresentar-se novamente para 0 exame, seis meses depois. A não obediência ao prazo também resultaria em penalidade sobre o juiz. Se, por outro lado, o artesão executasse a tarefa a contento e fosse aprovado, a "carta de exame" seria levada para a Câmara Municipal para ser vista, confirmada e registrada sob juramento e assinatura do escrivão. A partir desse momento, o artesão estava autorizado a exercer sua profissão e a montar tenda para vender seus produtos ou aceitar encargos (Correia, 1926: 1-3).

A execução de uma ou de uma série de tarefas específicas para o exame de cada profissão era estabelecida de modo geral pelos Regimentos e detalhada no momento do exame pelo juiz. Partíamos do pressuposto de que deveria haver, no manuscrito dos Regimentos conservado no Arquivo da Câmara de Lisboa uma série de desenhos ou modelos de peças que teriam de ser copiadas pelo artesão, uma vez que o texto se referia claramente à presença de desenhos: "E a pessoa que faça um gomil [jarro de boca estreita] como o que está adiante desenhado, maior ou menor, bem feito e acabado (...) [sem negritas no original] (Correia:1926: 17)", lia-se nas regras do exame dos ourives da prata.

Pode-se verificar, nas tarefas exigidas para o exame, de um lado, a ideia da imitação, cópia de modelos artísticos e artesanais; e, por outro lado, em alguns casos, a permissão para que 0 artesão criasse a peça com motivos ou formas segundo "sua invenção". No entanto, a peça, em geral, teria de ser executada de acordo com um modelo preestabelecido, um desenho, um cânone clássico - o desenho de uma coluna de ordem dórica com seu capitel e sua base, por exemplo, ou uma peça equivalente, um modelo tridimensional, realizada por outro artesão.

0 exame dos pedreiros exigia que 0 artesão realizasse, entre outros, justamente uma coluna dórica com sua base e capitel. Os ensambladores fariam um painel de sete palmos de altura e cinco palmos de largura, com sua moldura, utilizando cola feita de peixe e, depois, este painel teria que ser decorado com colunas dóricas, torneadas, bem proporcionadas e, sobre as colunas, teria que fazer um friso, com seus tríglifos, sua arquitrave e 
frontispício com proporções adequadas. Vários elementos indicam, nas exigências para os exames, a necessidade de conhecimento dos valores da arquitetura clássica - frontões, frisos, "as" ordens: colunas com sua respectiva tipologia de capitéis (Correia, 1926: 105 e ss.).

Para o exame de entalhador, o artesão deveria realizar um friso com ornamentos romanos, muito bem ordenados e, no centro, teria de esculpir:

um serafim muito bem feito e de formoso rosto e em tudo segundo a ordem e o desenho que aqui vai (...) Fará um capitel coríntio de um palmo de diâmetro e a altura será proporcionada a esta divisão, o capitel será ornado de folhas e caulículos muito bem feitos (...) na ordem das folhas e disposição de todo 0 ornamento deste capitel guardará as obrigações coríntias que em tudo seja conforme este desenho [sem negritas no original] (Correia, 1926:111).

Alguns exames, como vemos, exigidos aos aspirantes a oficiais, indicavam as possiveis aproximações dos trabalhos artesanais e a produção de peças detentoras de princípios artísticos eruditos. Este é o caso dos entalhadores, que eram obrigados a produzir um capitel coríntio em seu exame, para a emissão da carta.

Outro estatuto que viria a organizar o sistema de atuação dos artífices, publicado em Lisboa somente em 1767, foi o Regimento do Officio de Carpinteiro de Moveis e Semblage. Aqui são mencionados os exames para exercer 0 ofício, entre os quais o examinado deveria ser solicitado a executar "um retábulo de sete palmos ou como lhe determinar os juízes o qual levará suas colunas e será feito dentro do preceito da Arquitetura, ordenando os juízes de qualquer das cinco ordens, e desta ha de fazer a obra de exame" (Toledo, 2012: 146-149).

Parece ter havido, portanto, desde os Regimentos de 1572, uma clara referência aos Tratados de Arquitetura, especialmente àqueles de Giacomo Barozzi da Vignola (1508-1573) e de Sebastiano Serlio (1475-1554). As obras de Serlio, I Sette Libri dell'Architettura, de 1537 a 1571, as primeiras a codificar as cinco ordens clássicas; e o livro de Vignola, Regole delle cinque ordine dell'Architettura, de 1562, exerceram ambos enorme influência sobre o mundo ibérico, como se sabe, ensinando "a maneira" de projetar.

Os estudos de Ana Duarte Rodrigues vêm apontando a presença dos Tratados de Arquitetura em diferentes bibliotecas portuguesas dos séculos XV ao XIX e indicando um indubitável sistema de circulação dos tratados, especialmente aqueles de arquitetura, no universo artístico português (Rodrigues, 2011). Supõe-se, portanto, que além do ensino prático e em sintonia com este, os mestres artesãos transmitiam a seus aprendizes, para que se apresentassem 
aos exames e se tornassem oficiais, igualmente um refinado conhecimento teórico, de caráter erudito: um certo domínio e uma certa leitura dos tratados italianos e suas derivações que, com suas gravuras, circularam pelo mundo ibérico e cujas ideias chegaram até às distantes colônias. Segundo Rafael Moreira, alguns esforços da historiografia vêm contribuindo para desfazer "o enorme equívoco de imaginar a arte portuguesa imune à redação/leitura de tratados, hostil a princípios doutrinais e normas, incapaz de pensamento e teoria." E, ainda nas palavras de Rafael Moreira: "O fenômeno admirável da Tratadística moderna que percorre a Europa do século XV ao século XVIII, após a Itália do Renascimento e sua descoberta de Vitrúvio (25 a.C.) não deixou Portugal à margem, como repetia a doutrina aceite por pura inércia" (Moreira, 2011:8).

Com relação à historiografia da arte brasileira colonial, a implementação do sistema de controle das atividades artesanais é corretamente relativizada por autores como Caio Boschi (1984) e Jeaneth Xavier Araújo (2005), uma vez que tal sistema foi adaptado à realidade da Colônia. Deve ser considerado, portanto, que as regras contidas no Livro dos Regimentos não foram rigorosamente aplicadas nem mesmo em Portugal e tanto menos na distante Colônia.

(...) Pelos preceitos corporativos, nenhum oficial podia assumir obra pertencente a outro ofício. Provavelmente nem mesmo em Portugal esta norma foi rigidamente respeitada por parte dos mecânicos não havendo divisão rígida dos ofícios similares (escultor/entalhador, carpinteiro/carapina, pintor/dourador), ocorrendo a muitos destes profissionais agirem de acordo com a demanda [sem grifo no original] (Araújo, 2005:41-44)

Em detrimento dos exames de ofício e seu registro, os artesãos atuaram em grande medida sob o regime das licenças e na esfera da informalidade. No entanto, a volumosa documentação que se encontra, por exemplo, no Arquivo da Câmara de Mariana, em Minas Gerais, relativa ao registro de exames de ofício e toda a documentação referente às eleições e atuação de juízes de ofício, comprova que houve (se não de fato, ao menos de direito) a implementação das regras dos Regimentos dos Oficiais Mecânicos.

No que se refere ao conjunto de preceitos transmitidos pelos tratados de arquitetura do Renascimento italiano para 0 mundo ibérico, que pode ser notado pelas exigências dos exames de ofícios, entre os elementos canônicos, estarão justamente destacadas as chamadas ordens clássicas. A partir de Serlio, as cinco ordens tiveram suas características aritméticas e geométricas e sua decoração escultórica fixada. Para Joseph Rykwert, em seu livro "A Coluna Dançante: sobre a ordem na arquitetura": arquitetos, construtores, pedreiros, carpinteiros - qualquer indivíduo ligado à construção - iriam adquirir pelo menos um deles [tratados de arquitetura], mesmo que por vezes não 
fossem mais que folhas avulsas para uso nas oficinas [grifo nosso]", e também as colunas e suas cinco ordens seriam o elemento maior e a prova visível da adoção de princípios universais, "copiadas por pedreiros e carpinteiros como modelo, sem qualquer referência ao texto". (Rykwert, 2014: 26-27)

Por outro caminho, para se compreender a circulação do conhecimento dos tratados de arquitetura no ambiente dos artesãos, Julius Schlosser havia indicado a existência da transmissão de saberes eruditos contidos em tratados como os de Serlio e Vignola, por livros simplificados, publicações "populares", escritas e lidas sobretudo entre carpinteiros, ebanistas e entalhadores, capazes de reduzir os elementos arquitetônicos às dimensões dos retábulos, móveis ou caixas. Em oposição à literatura aristocrática, marcada pelo ambiente de corte, Schlosser evocava sua correspondente alemã, limitada ao ambiente artesão e pequeno burguês, como libretos populares sobre as cinco ordens, os chamados, mais tarde, Säulenbuchlein. Alguns desses "tratatelos" ainda guardavam semelhanças aos scapellini góticos, mas já dependiam de Vitrúvio e especialmente de Serlio, como, por exemplo, o livro de Hans Blum, Buch von den fünff sülen, editado em latim, em Zurique em 1550 e em alemão em 1554. A edição em latim desse livro propiciou sua difusão também nos países baixos e latinos (Magnino, 2000: 411-413; 418).

Em 1565, o chamado "Vitruvio Flamengo", Vredeman de Vries publicou nos Países Baixos seu livro L'Architectura. A absorção destes livros por ebanistas diletantes (a palavra vem na nobre madeira, o ébano, e quer dizer marceneiros especializados em móveis de luxo) de Augusta e Nuremberg, levou à construção em pequenas dimensões de templos domésticos, móveis, cassoni, armários - com aspecto absurdamente monumental, baseado nos princípios de Vitrúvio, Serlio e Vignola e elaborados com elementos arquitetônicos como as colunas das ordens clássicas. Um dos últimos desses escritos foi publicado em Viena justamente por um ebanista, Johann Indau, em 1686 (Magnino, 2000:413).

As Regras das Cinco Ordens de Arquitetura, de Vignola, publicado 1562, foi 0 livro do gênero que obteve o maior sucesso editorial, segundo Schlosser, suplantando o sucesso de Serlio na primeira metade do século XVII e também superando, em muito, os grandes tratados de arquitetura de Palladio e Scamozzi. Isso se deveu, talvez, a sua forma sóbria e acessível, cujo uso foi recomendado nas escolas, como livro didático, pelo qual foi infinitas vezes reeditado, traduzido em todas as línguas. O livro de Vignola se tornou, definitivamente, o manual do estudante e diletante em arquitetura por séculos.

As Regras consistem num livro didático, segundo Schlosser, tanto no bom quanto no mal sentido: ideias claras, sóbrias, objetivas, bem dispostas, mas 
feitas de fórmulas e sem vida. Entram diretamente no tema das cinco ordens como um "abc" de toda vera arquitetura regular e, pela primeira vez, este livro fundou o dogma do sistema das cinco ordens, em grande parte arbitrário e anti-histórico. Schlosser considera, ainda, ter havido o que ele chamou de "absorção ingênua de Vignola", sobretudo ao norte da Itália, a partir do século XVII, como um catecismo, especialmente nas "artes industriais decorativas" (Magnino, 2000: 410-411;421-422).

O século XVIII vê um interesse renovado pela Antiguidade, suas medidas exatas e seu conhecimento preciso por um olhar arqueológico, bem como por seus elementos emblemáticos, entre os quais especialmente as colunas e as "ordens clássicas" que haviam adquirido uma validade atemporal (Rykwert, 2015:14). Em meio às publicações deste novo contexto, que atualizavam e facilitavam a leitura dos tratados de arquitetura e a didática das "ordens", caberia citar Regras das Sinco Ordens da Architectura segundo os princípios de Vignhola com um ensaiosobre as mesmas ordens feito sobre o sentimento dos mais célebres Architectos escriptas en Francez por ${ }^{* * *} e$ expostas em Portuguez por J.C.M.A. (...) enriquecida com 88 estampas abertas em cobre. Sem revelar 0 autor do livro em francês, a publicação sai, em língua portuguesa, como de autoria identificada apenas pelas inicias de J.C.M.A. e tradução ao português por Antonio Barnicaud, dedicado ao Bispo de Coimbra, datada de 1787. As Regras das Sinco Ordens parecem seguir a estrutura expositiva e didática semelhante à do livro publicado no ano anterior, em 1786, em Paris: Regles des Cinques Ordres de l'Architecture de Vignole de ClaudeMathieu Delagardette, arquiteto e aluno da Academie Royale d'Architecture de França.

Nossa hipótese, seguindo a pista sugerida por Benedito Lima de Toledo, no pequeno texto "A obra de Serlio e Vignola e os Regimentos de Ofícios", publicado originalmente como capítulo do grande livro organizado por Walter Zanini, História geral da arte no Brasil, é de que houve no Livro dos Regimentos de 1572 e nos Regimentos de Carpinteiros de Móveis e Semblagem de 1787 a confirmação da circulação e da obrigatoriedade do conhecimento dos tratados de arquitetura do século XVI italiano e das ordens clássicas para o universo do trabalho artesanal português (Zanini, 1983:167; Toledo, 2012: 146-149).

O problema residia, porém, no fato de que, ao se transcrever e publicar o Livro dos Regimentos, em 1926, as ilustrações - se as houvesse - não foram reproduzidas; o que nos impedia de comparar os modelos em desenho de obras exigidas para o exame com aqueles cânones arquitetônicos contidos nos Tratados de Arquitetura do tardo-Renascimento, também ilustrados com gravuras. Fomos, portanto, em busca do documento original manuscrito de

3 O texto de Benedito Lima de Toledo foi reeditado no livro Esplendor do Barroco Luso-Brasileiro (Toledo, 2012) 
uma das cópias do Livro dos Regimentos existente no Arquivo Municipal da Câmara de Lisboa, em Portugal, para procurar as supostas ilustrações contidas ou avulsas e ou, ao menos, as marcas deixadas por estes "desenhos" que não constavam na transcrição realizada na década de 1920, porém sugeridas claramente pelas expressões: "como o que está adiante desenhado". Como vimos, em vários termos dos exames, exigia-se a execução de determinadas peças "conforme desenho abaixo" ou "como 0 desenho que aqui vai" (Correia, 1926).

No entanto, a transcrição de 1926 fora realizada sem a reprodução das ilustrações não por uma omissão, mas porque, justamente, como se confirmou pela observação do manuscrito, não havia ali contidos os tais desenhos aos quais o texto se refere. Esta ausência de ilustrações no Livro dos Regimentos frustrou nossa expectativa de encontrar, ali contidos, os desenhos que teriam servido de modelo para os artesãos no momento do exame. O manuscrito não possuía as ilustrações as quais ele mesmo mencionava e nem mesmo espaços em branco que pudessem contê-las coladas. $O$ elemento surpresa, talvez, consistia em que o examinado não saberia de antemão, antes de apresentar-se para o exame, qual desenho ou modelo deveria especificamente seguir. Este modelo, ou desenho, não era sempre o mesmo e lhe era apresentado separadamente no tempo certo e à escolha do juiz. Mas resta saber: que desenhos seriam estes? Seriam pranchas avulsas, ilustrações copiadas, gravuras ou desenhos propriamente ditos?

Ana Duarte Rodrigues, em seu texto "A Circulação dos Tratados de Arte em Portugal" indicou um possivel caminho de resposta ao tratar do exercício de cópias manuscritas dos tratados de arquitetura impressos, cujas edições se encontravam em algumas valiosas bibliotecas que eram visitadas, para 0 estudo e reprodução manuscrita dos textos e imagens dos Tratados por parte de artistas e artesãos especializados (2011: 29). Tais desenhos não apareceram no manuscrito primordial de 1572, do Arquivo da Câmara de Lisboa, o que nos leva a crer que eles constituíssem, de fato, objetos avulsos. $\mathrm{Na}$ Biblioteca Nacional de Lisboa localiza-se um importante acervo de aproximadamente cinquenta desenhos, anônimos em sua maioria, classificados como "estudos arquitetônicos" que representam justamente colunas e capitéis. Nossa hipótese caminha no sentido de averiguar 0 significado de tais desenhos, sua relação com os tratados de arquitetura do Renascimento e a possibilidade de que tenham servido de modelo para os exames dos oficiais mecânicos.

Ayres de Carvalho publicou o Catálogo da Coleção de Desenhos da Biblioteca Nacional de Lisboa em 1977. Naquele momento, realizou uma classificação temática e tipológica dos desenhos. Uma dezena deles - datada desde 0 século XVII ao início do XIX - foi classificada como "desenho arquitetônico", todos anônimos, considerados pelo autor do catálogo como "estudos de um 
aluno de arquitetura das academias portuguesas" (Carvalho, 1977: 48-54). A grande maioria dos desenhos, em tinta china e aguada, constituiu-se de folhas avulsas de diferentes tamanhos, desde papéis de trinta por quarenta centímetros até mesmo folhas de pequeno formato de aproximadamente oito por doze centímetros. Alguns foram identificados pela marca do papel ou pelas anotações que continham como sendo de procedência francesa. Chama a atenção, nesta coleção, o exemplar de um caderno com vinte e seis estudos de desenho arquitetônico que mencionam explicitamente terem sido copiados do Tratado de Vignola [fig. 1]. Nota-se também um pequeno desenho com medidas das colunas e diversas e insistentes anotações à lápis [fig. 2]. Há também um dos desenhos cuja autoria pode ser identificada por assinatura como de Nunes Lopes Manuel. Trata-se de um estudo da Ordem Coríntia com muitas legendas indicando a maneira de executar o desenho, fazendo referências ao Tratado de Vignola [fig. 3].

Esta ordem Corintia pa. Se fazer se ade devidir toda a altura em trinta e duas partes os quas se lomeio por moldes. Estes models se devidem Em 48 partes iguais cada hu... sem pedestaç se ade de dar de largo o vão do Arco... comforme Vignola folhas"... (apud Carvalho, 1977: 53)

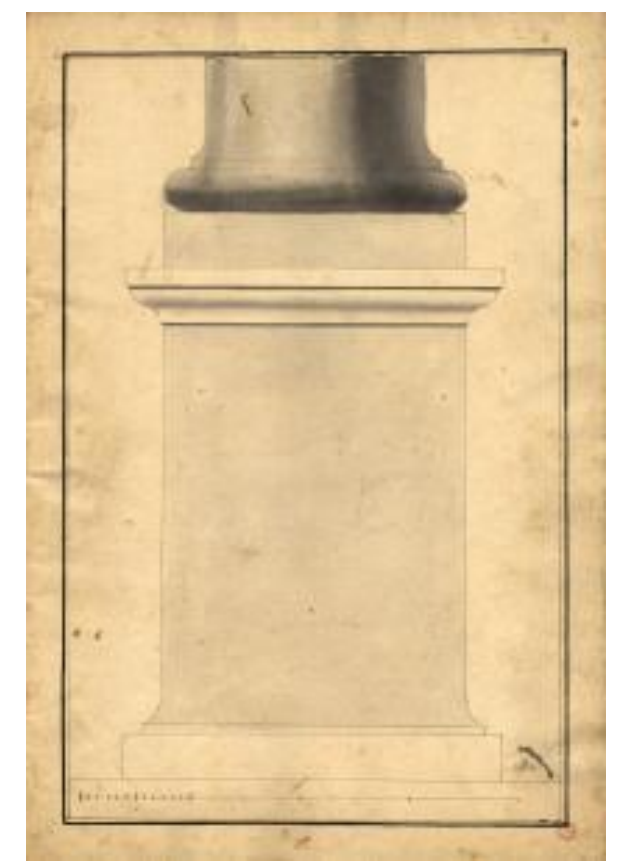

Fig. 1. [Caderno de desenho arquitectónico] : [estudos] [entre 1750 e 1800]. - [l], 26 f.: 26 desenhos a tinta da china e aguadas; $43 \times 30 \mathrm{~cm}$. Biblioteca Nacional de Portugal. Fonte: http://purl.pt/25341 


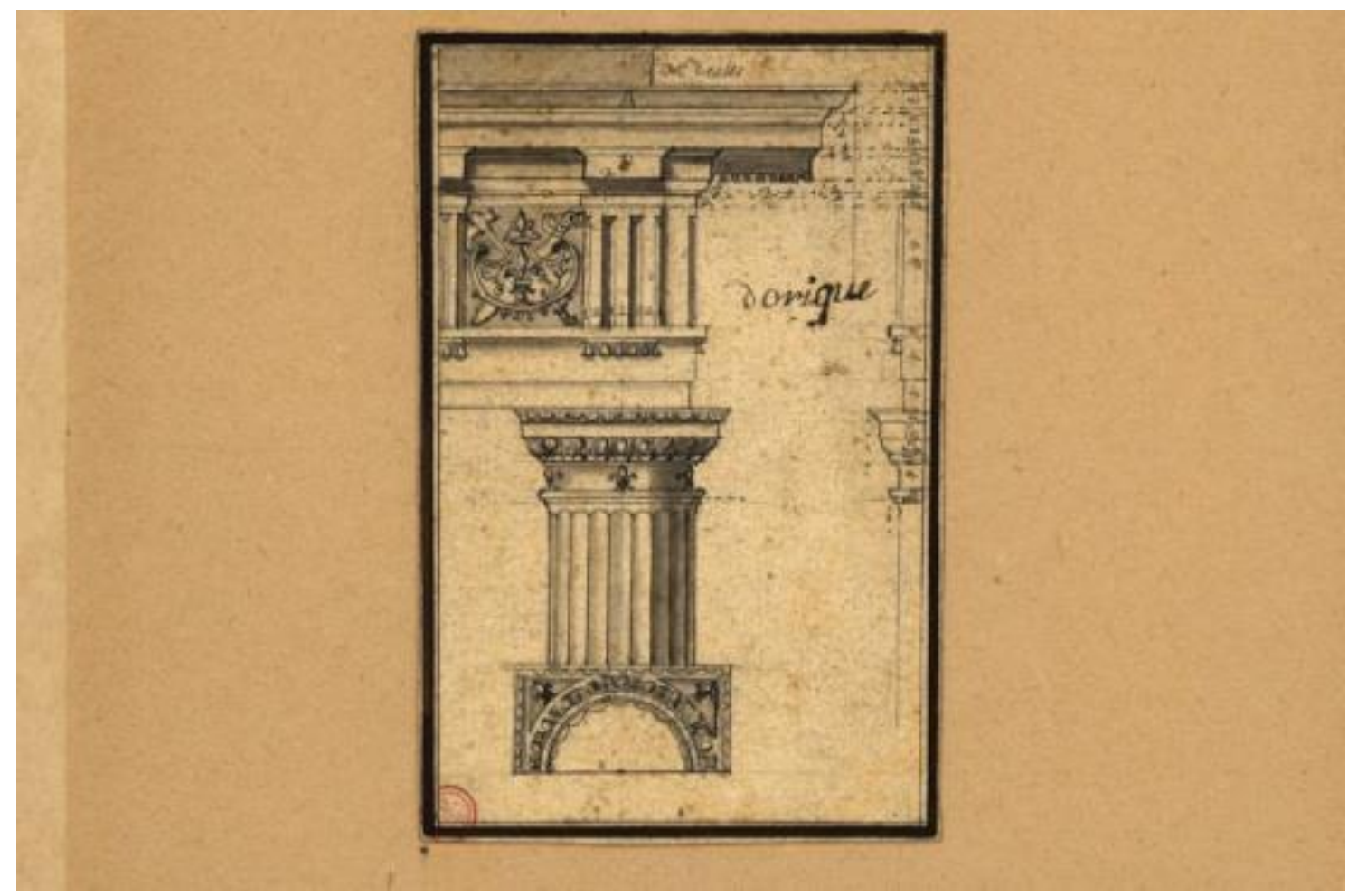

Fig. 2. [Estudo arquitectónico]: [entablamento da Ordem Dórica] [17--]. - 1 desenho: tinta da china e aguadas; $82 \times 12,7 \mathrm{~cm}$

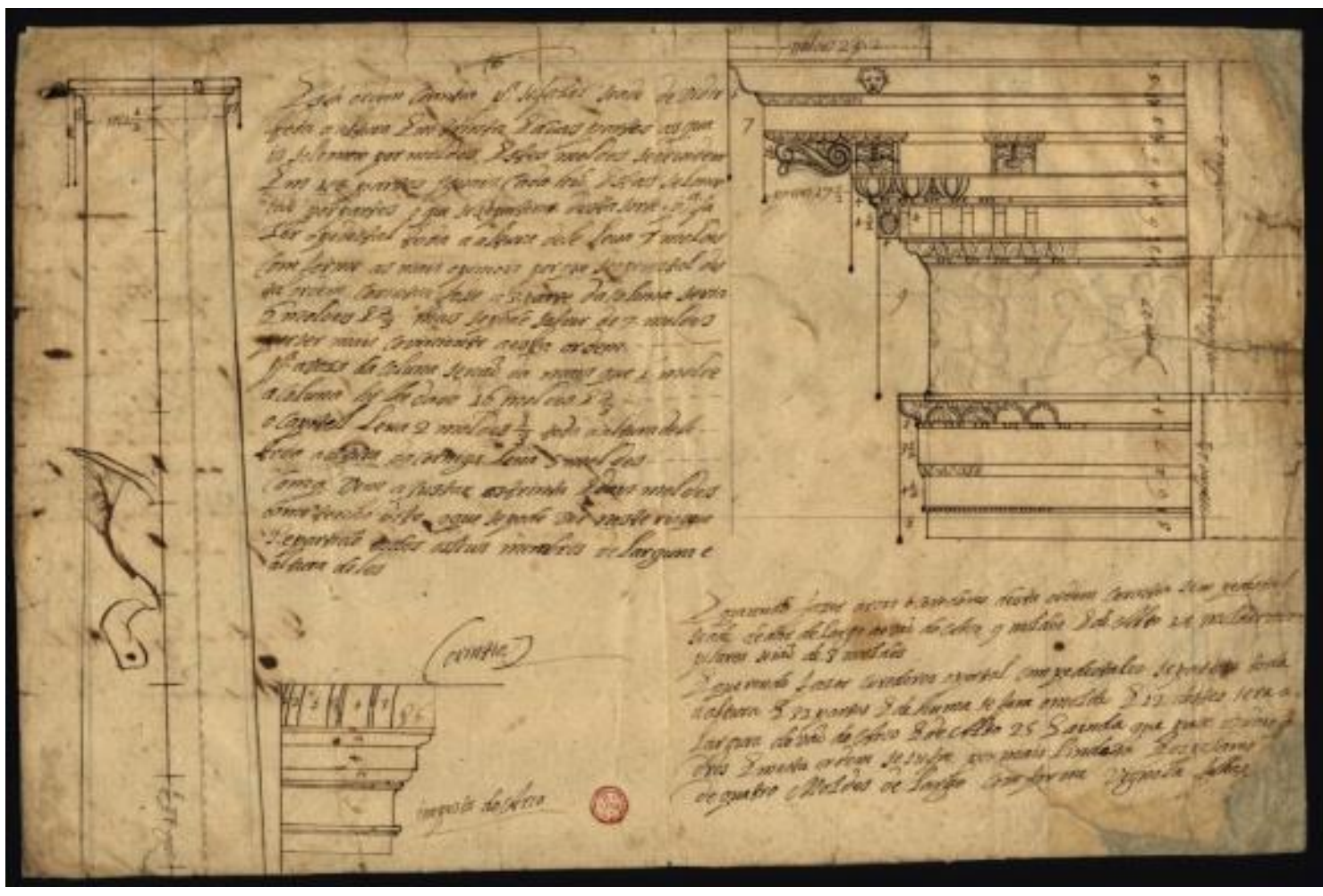

Fig. 3 - LOPES, Manuel Nunes, fl. 17-- [Estudo arquitectónico]: [entablamento da Ordem Coríntia]. [17--]. - 1 desenho : tinta sépia ; 31,7 x 21,1 cm. Fonte: http://purl.pt/25345 
Muitos desses desenhos possuem marcas no papel que sugerem ter sido, em algum momento de sua trajetória, manuseados intensamente. Talvez os desenhos da Biblioteca Nacional de Portugal não possam resolver facilmente o problema dos desenhos indicados, mas inexistentes, no Livro dos Regimentos, mas se trata apenas de levantar uma hipótese em construção. De qualquer modo, por seu volume e uniformidade, os desenhos classificados como "estudos arquitetônicos", conservados na Biblioteca Nacional de Portugal, podem corresponder, como indicou Ayres, a exercícios de alunos da academia. No entanto, conhecendo a história tardia e conturbada para a afirmação do ensino acadêmico da arte e arquitetura em Portugal e a permanência do sistema de trabalho artesanal, podemos cogitar que tais desenhos pertencessem, ao menos em parte, ao universo dos artesãos.

Ainda está por ser esclarecida a dinâmica de transferência dos preceitos artísticos da tratadística italiana por meio de desenhos, especialmente no que se refere às ordens clássicas contida nos tratados de arquitetura (como os de Serlio e Vignola), em direção do sistema artístico luso-brasileiro. Tal sistema, como foi apontado, caracterizava-se, ainda durante o século XVIII, pela permanência de controle dos trabalhos de oficiais mecânicos como atores das empreitadas artísticas. Marceneiros, carpinteiros, ensambladores, entalhadores, artesãos que se aplicaram às obras artísticas em madeira, submetiam-se aos exames de ofício para exercer suas funções. Os exames consistiam, pelo que se pôde observar no Livro dos Regimentos, no domínio de formas artísticas clássicas, as ordens, contidas em menções explícitas aos enigmáticos desenhos.

A revelação da circulação deste conhecimento teórico e estético, advindo dos tratados de arquitetura italianos do Renascimento e suas derivações, por meio das exigências dos exames de ofício e dos desenhos que serviriam de modelos para a execução das peças possibilitará uma compreensão mais clara dos procedimentos artísticos no Brasil Colônia, suas referências, suas matrizes estéticas e estilísticas e os mecanismos de transmissão de modelos europeus para a arte colonial brasileira. Parece claro que, ao lado de um aprendizado prático do fazer artístico dos artesãos nos canteiros de obras e ateliês, havia um refinado conhecimento teórico e erudito, referente ao domínio dos cânones da arquitetura clássica, especialmente o conhecimento das "ordens", por meio da divulgação dos tratados, ainda que, muitas vezes, fracionados em desenhos.

\section{Referências}

ARAÚJJO, Jeaneth Xavier de. A pintura de Manoel da Costa Ataíde no contexto da época moderna. In CAMPOS, Adalgisa Arantes. Org. Manoel da Costa Ataíde: 
aspectos históricos, estilísticos, iconográficos e técnicos. Belo Horizonte: C/Arte, 2005. P. 50.

BAROZZIO DA VIGNOLA, Giacomo. Regla De Las Cinco Ordenes De Arquitectura. Madrid: Colegio de Aparejadores, 1997.

BOSCHI, Caio C. O Barroco mineiro: artes e trabalho. São Paulo: Brasiliense, 1984.

BRANDÃO, Angela. Tratados de Arquitetura e o Livro dos Regimentos: uma sutil referência In: Anais do XXXIV Colóquio do Comitê Brasileiro de História da Arte Territórios da História da Arte. Uberlândia: Comitê Brasileiro de História da Arte, 2014. v.1. p. $429-436$.

CAMPOS, Adalgisa Arantes. Introdução ao Barroco Mineiro. Belo Horizonte: Crisálida, 2006.

CARVALHO, Ayres de. Catálogo da Colecção de Desenhos. Lisboa: Biblioteca Nacional de Lisboa, 1977.

CORREIA, Vergílio. Prefácio. Livro dos Regimentos dos officiaes mecanicos da mui nobre e sëpre leal cidade de Lixboa -1572. Publicado e prefaciado pelo Dr. Vergílio Correia. Coimbra: Imprensa da Universidade, 1926.

DA COSTA, Félix. Antiguidade da Arte da Pintura, sua nobreza, Divino e Humano que a exercitou e honras que os Monarcas fizeram a seus Artifices, 1685-1688

DA COSTA, Félix. The Antiguity of Painting by Felix da Costa. Introduction and notes by George Kubler. New Haven and London. Yale University Press, 1967.

DELAGARDETTE, C.M. Regles des Cinques Ordres de l'Architecture de Vignole. Paris: Chereau, 1786.

DOMENECH, F.; BRANDAO, A.; YANG, K. K. B. O açúcar nas festas barrocas: a arte efêmera nos séculos XVII e XVIII. In: Encontro de História da Arte - Unicamp, 2014, Campinas. Estudos transdiciplinares e métodos de análise, 2014. (A)

DOMENECH, F. ; YANG, K. K. B. Arte efêmera nos séculos XVII e XVIII: a estética da alimentação. In: XXII Congresso de Iniciação Científica - PIBIC, 2014, São Paulo. Arte efêmera nos séculos XVII e XVIII: a estética da alimentação, 2014. (B)

J.C.M.A. Regras das Sinco Ordens da Architectura segundo os princípios de Vignhola com um ensaiosobre as mesmas ordens feito sobre o sentimento dos mais célebres Architectos escriptas en Francez por ${ }^{* * *}$ e expostas em Portuguez por J.C.M.A. (...) enriquecida com 88 estampas abertas em cobre. Coimbra: Real Imprensa da Universidade, 1787.

Livro dos Regimentos dos officiaes mecanicos da mui nobre e sëpre leal cidade de Lixboa -1572. Publicado e prefaciado pelo Dr. Vergílio Correia. Coimbra: Imprensa da Universidade, 1926

MAGNINO, Julius Schlosser. La Letteratura Ariistica. Milano: Paperback Classici, 2000. 
MOREIRA, R. e RODRIGUES, A.D. coord. Tratados de Arte em Portugal. Lisboa: Scribe, 2011.

MOREIRA, Rafael. 0 mundo dos Tratados. Apresentação in MOREIRA, R. e RODRIGUES, A.D. coord. Tratados de Arte em Portugal. Lisboa: Scribe, 2011, pp. 719.

OLIVEIRA, Myriam Andrade Ribeiro de. O Rococó Religioso no Brasil: e seus antecedentes europeus. São Paulo: Cosac \& Naif, 2003.

SERLIO, Sebastiano. SEBASTIANO SERLIO ON ARCHITECTURE BOOKS I-V OF 'TUTTE L'OPERE D'ARCHITETTURA ET PROS. Yale University Press, 2005

TOLEDO, Benedito Lima de. A Influência dos Tratadistas, a Obra de Serlio e Vignola e os Regimentos de Orfícios. Esplendor do Barroco Luso-Brasileiro. Cotia -SP, Ateliê Editorial, 2012.

TOLEDO, Benedito Lima de. Do Século XVI ao início do Século XIX: maneirismo, barroco e rococó. (A obra de Serlio e Vignola e os Regimentos de Ofícios). In ZANINI, W. História Geral da Arte no Brasil. São Paulo: Instituto Walther Moreira Salles, 1983. Vol. 1, pp. 167-175. 